\title{
Fashion Cultural Product Designs Using Artifacts Excavated from the Iksan Mireuksaji
}

\author{
Hye Kyung Kim ${ }^{1) \dagger}$ and Jeong Hwa Hong ${ }^{2)}$ \\ ${ }^{1)}$ Dept. of Fashion Design \& Industry, Wonkwang University; Iksan, Korea \\ ${ }^{2)}$ Dept. of Fashion Coordination, Jeonju-kijeon College; Jeonju, Korea
}

\begin{abstract}
The aim of this study is to develop fashion cultural product designs in order to promote the Iksan region by using motifs from the Mireuksaji, Iksan's most representative archeological site of Baekje culture. The fashion cultural products designs developed by applying cultural resources can be effective at enhancing our cultural identity. Adobe Illustrator CS4 and Adobe Photoshop CS4 were used to reconstruct motifs from the Sumakse tiles and the bronze horse figure in the Mireuksaji Museum. The Iksan brand slogan "Amazing Iksan" was combined with the bronze horse to emphasize the local cultural identity. The motifs from the Mireuksaji were modified and stylized to make different patterns and these patterns were repeated in various ways to be applied to necktie and scarf designs. The motifs for necktie designs were double-row chrysanthemum tiles and phoenix tiles, and the motifs for scarf designs were the double-row lotus tiles and the bronze horse artifacts. Different colorways were chosen and the value of each color was displayed in the CMYK percentages. As a result, eight necktie designs and twelve scarf designs were proposed. The motifs and patterns developed in this study can be used to introduce Iksan's distinct history as the birthplace of Baekje culture. It is also expected that the result of this study can advance the promotion of Korean traditional culture internationally.

Key words : Iksan Mireuksaji, fashion cultural product, Baekje culture, necktie design, scarf design
\end{abstract}

\section{Introduction}

In the information age of the $21^{\text {st }}$ century, culture is not simply a way of understanding humans but an indispensable requirement for enhancing a country's competitiveness. Diverse cultural elements are important resource for marketing because they create added value by stimulating consumers' emotions. Cultures of the world can be shared globally in this information age. The information age of society serves to both compress the diverse amalgam of cultural identities into a singularity as well as recognize the unique aspects of each identity, thus retaining individuality. Hence, the competitiveness needed in order to target a global market will be enhanced by modernizing native cultural products and fashioning Korean traditional beauty into cultural commodities, rather than the production of average products.

Cultural products are considered to be idea-intensive goods, adding the value of culture, skill, and creativity then creating a higher value-added product. Additionally, in the process of developing new products the ever-important general consumer's satisfaction must be managed by engineering an organic balance between major advancements in the scientific field as well as aesthetic forms coming from the arts. Among cultural products,

†Corresponding author; Hye Kyung Kim

Tel. +82-63-850-6645, Fax. +82-63-850-7301

E-mail: hanel@wonkwang.ac.kr fashion cultural products are especially high-value visual cultural products and if our culture's originality and our country's image are invested in them we can enhance our cultural identity and our country's competitiveness, simultaneously satisfying the consumer's desires for fashion. We must also recognize that fashion products are cultural products and should retain the variety, distinctiveness, and originality that fashion is known to provide. Therefore fashion cultural products that are sold at tourist destinations must fit our contemporary sentiments and tastes along with the changing patterns of demand and the regional characteristics and traditions.

Specifically, textiles developed utilizing traditional culture should be used as raw materials for clothing, fashion accessories and cultural products. This approach can add value to the products by giving them an inherent image and originality. Also, Korea's traditional culture is an important cultural inheritance that contains the nation's sentiments, whilst being representative of its aspirations and origins. Therefore the regional cultural heritage can be recognized as an aspect that reflects our culture's aesthetics, it can be practically applied as a design tool that expresses decorative desires, whilst naturally having high sociability compared to other aspects. The relationship between fashion cultural products blended with the region's cultural resources and a region's cultural identity is complementary and is effective at promoting our traditional culture. However, the fact is there are not many cultural products that show the excellence of the Baekje culture and promote Iksan as a representative of Baekje culture. The 
Table 1. Artifacts applied to motif construction

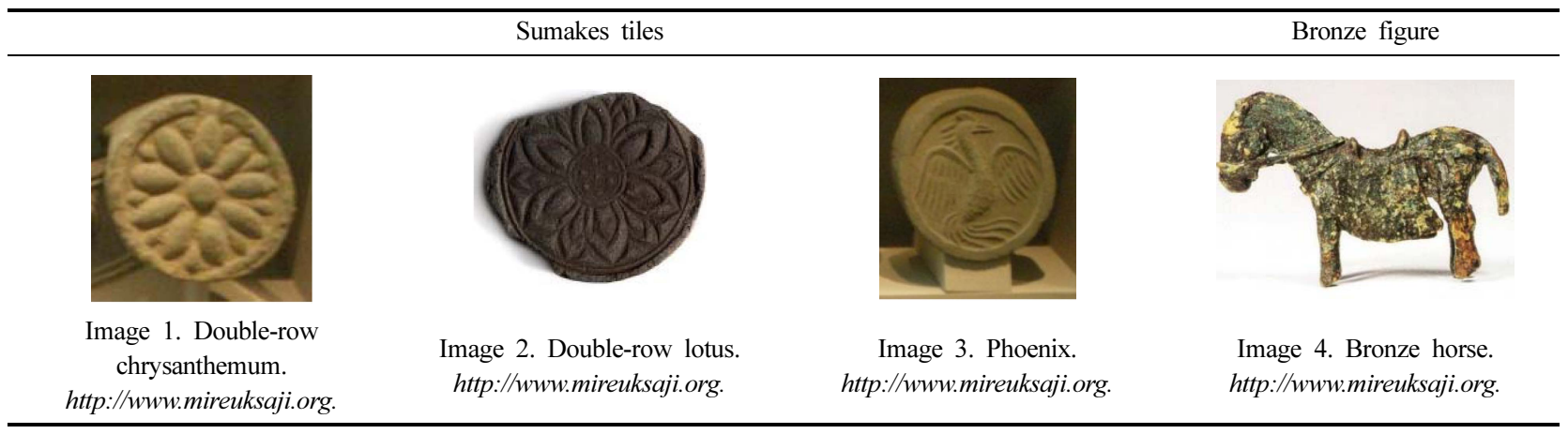

development of cultural tourism products that fuse Iksan's cultural identity with the region's culture is needed.

Consequently this study attempts to develop motifs and make textile patterns that appeal to the consumer's emotions, centering around artifacts from the Mireuksaji, Iksan's representative historic site, that forms the heart of the Baekje culture. The study's purpose is to publicize Iksan's traditional culture and recognize that Iksan as the birthplace of Baekje culture in a new light. Adobe Illustrator CS4 and Adobe Photoshop CS4 were used to reconstruct motifs using artifacts that are shown in the Mireuksaji Exhibit Hall and to develop textile patterns by repeating these motifs. These patterns were then applied to necktie and scarf designs that are to be used as fashion cultural products. A total of four motifs were chosen and reconstructed from Sumakse tiles that were used as part of the wooden architecture of the Mireuksaji: chrysanthemum, lotus, phoenix, and bronze horse figure(Table 1). The four reconstructed motifs were applied to a repeating pattern each using one of four colorways, and a total of twenty products including designs for eight neckties and twelve scarves were presented for fashion cultural products.

\section{Review of Literature}

\subsection{The Mireuksaji historic site in Iksan}

The Iksan Mireuksa( 彌勒寺 ) was built as a national temple by
King Mu( 武王, A.D. 600-641) and is located south of the Mireuk mountain in Kiyang-ri, Keum-ma-myun, Iksan. The Mireuksaji is a historical site that received attention from many scholars after geological studies conducted in the early $20^{\text {th }}$ century. The Mireuksaji was first excavated in April and May of 1966. The building was exposed by residents at the time who were trying to fill in the water reservoir at the rear of the Mireuksaji West Tower. The construction of the water reservoir was halted and a temporary investigation was conducted. In 1974 and 1975, the Mahan Baekje Cultural Institute at the Wonkwang University started the excavation of the East Tower and revealed that a stone pagoda identical to the West Tower existed. Then the complete excavation was done by the National Treasure Institute.

There are the National Treasure No.11, the Mireuksaji stone pagoda, which is considered the largest in Korea, the Treasure No.236, the Dangganjiju, the Provincial Cultural Asset No.143, the Seokdeunghadaeseok, and many building sites, kiln sites, workshops, and ponds at the Mireuksaji(The National Historic Site No. 150). The Mireuksaji Artifact Museum is located southwest of the Mireuksaji. The Mireuksaji Artifact Museum has a total of 19,000 articles in its collection centering around 394 artifacts including those of glass, bronze, iron, stone, wood, roof tiles, clay, ceramic pottery, and Buddhist crafts(Table 2).

In Iksan, there are archeological sites other than the Mireuksaji including the Wanggungri Remains and the Iksan Mud Rampart

Table 2. The Mireuksaji artifacts
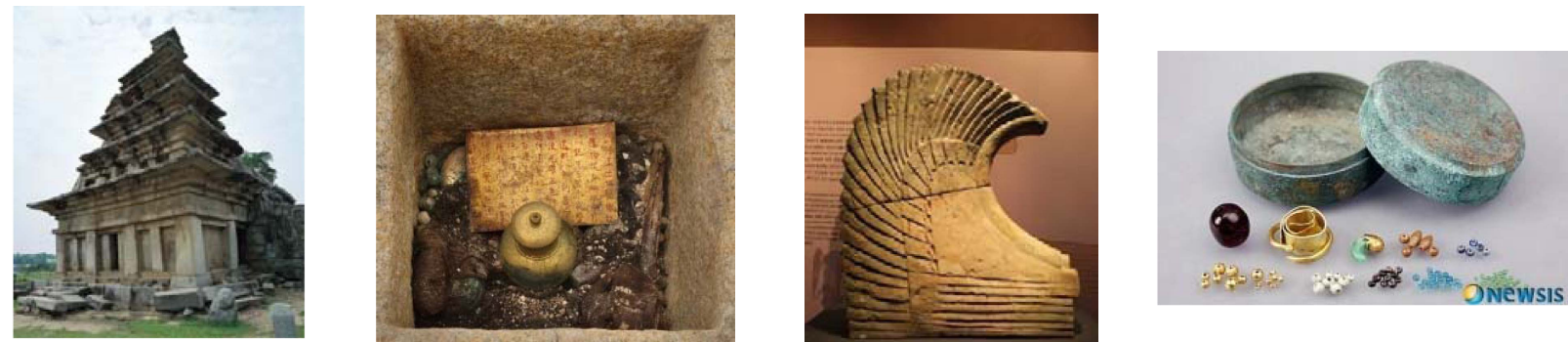

Image 5. Mireuksaji Stone Pagoda. Image 6. Sarijangum of Mireuksaji. Image 7. Chimi(Roof Decoration). Image 8. Bronze Box and Containing http://www.nrich.go.kr. http://www.nrich.go.kr.

http://www.mireuksaji.org Artifacts. http://www.newsis.com 
Table 3. Cultural resources of Iksan

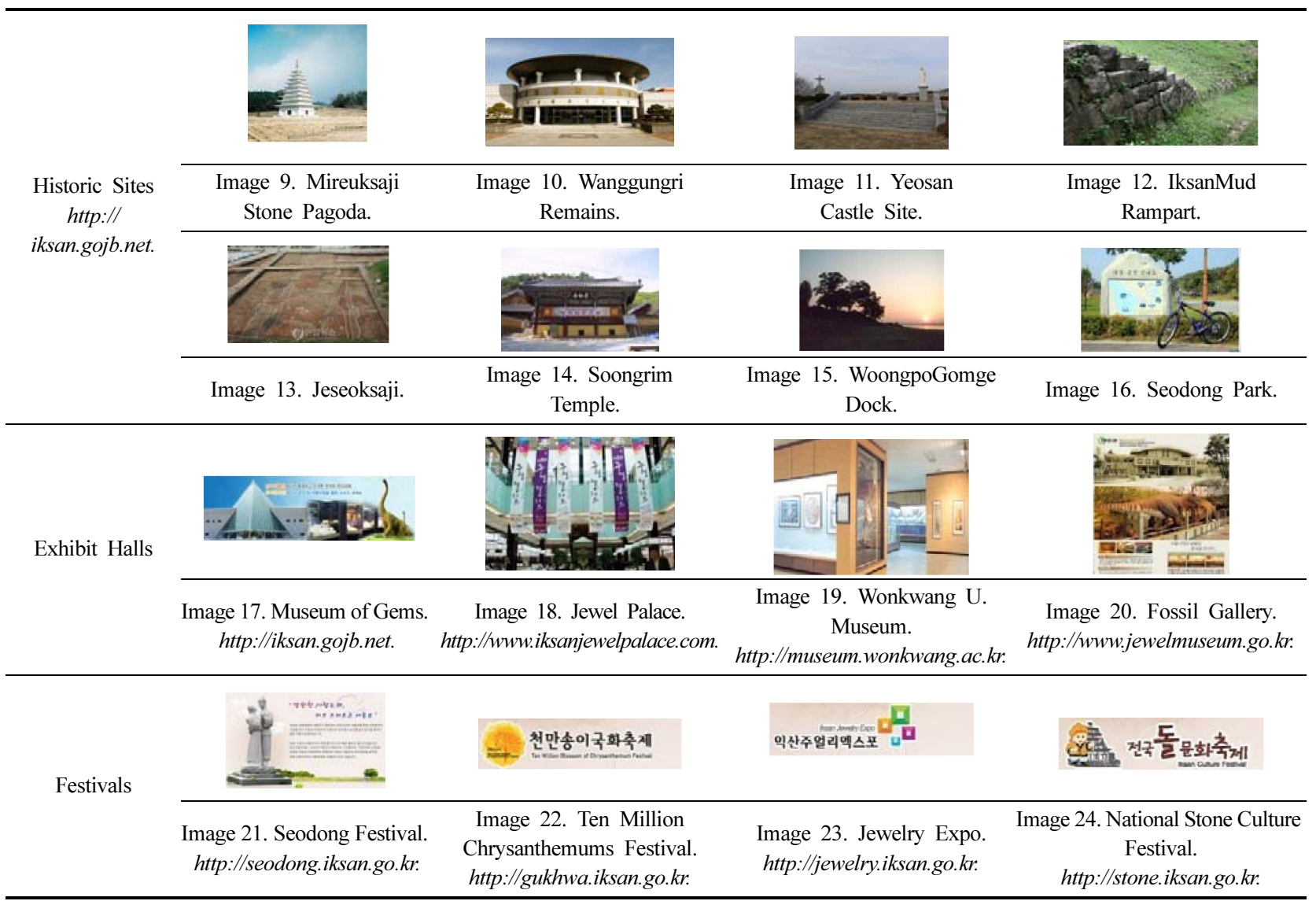

and galleries such as the Jewel Museum and Fossil Gallery. Iksan City is making efforts to promote the region's cultural resources and publicize that Iksan is the home of the Baekje culture by using four festivals: the Seodong Festival, the Ten Million Chrysanthemums Festival, the Jewelry Expo, and the National Stone Culture Festival. These four festivals are combined with many different tourist experiences that are centered around the participants in order to attract more tourists(Table 3).

\subsection{Designing cultural products}

In the $21^{\text {st }}$ century there has been a heightened awareness of culture. And the countries around the world have deemed it an essential driving power of national development and have established policies and concentrated investments on promoting culture. Currently the market for cultural industry has increased worldwide including Korea and accounts for a large percentage of tourism cultural goods. Most of the cultural goods include craft goods such as ceramics, stationery, pottery, specialties and fashion goods. The majority of fashion goods include accessories and jewelry such as earrings, necklaces, rings, bracelets and hair accessories, and clothing include t-shirts, hats, neckties, and scarves. The majority of former research on cultural product development is on designs using traditional patterns as motifs and research on clothing-related fashion cultural products linked with cultural tourist resources has not been done extensively, but most of the former research is divided into product design based on cultural resources or the design of tourist products for local festivals.

First, who held Lee(2002), a previous study based on the region's cultural resources, used a butterfly as the symbol for the Hampyeong region representing the clean natural environment. The study developed this symbol into the region's cultural resource and differentiated it from other regions by emphasizing the clean natural environmental image and developed it into a tourist cultural product that not only advertised the region but enhances its competitiveness supporting the region's economy. During the process of determining which products to develop, the researcher took a survey of the residents of Hampyeong and the tourists that visited the Hampyeong region and decided upon scarves, blouses, and neckties.

Following the increase in tourists to the beaches of the southwest regions due to the opening of the Western Coast Highway and the KTX train, Kang and Cho(2010) developed and proposed neckties 
that show the distinct characteristics of island and ocean culture as marine culture tourist products. In order to utilize the distinctiveness of the marine image, they extracted and stylized distinct colors, shapes, and textures using pictures of waves, marine life(octopus, jellyfish, starfish, etc.), and islands. Allowing those marine images to be expressed to the fullest, they implemented craft dying techniques such as tie-dye techniques and the DTP technique, then applied the resulting product to the neckties and analyzed the effects. Kim(2011) proposed fashion cultural product design that combined the characteristics of the Yeosu region with the opening of the 2012 Yeosu World Expo. The study did not stop at cultural product development that was based on the Expo's logos or symbols but developed unique designs that fused with the motifs for the region's cultural resources. Using symbols that represented Yeosu as motifs, the study proposed distinct designs that combined the region's traditions and culture along with an international touch. In this article, the motifs were developed and applied on items such as neckties, handkerchiefs and t-shirts.

In addition, studies on designs that focused on cultural products for regional festivals include Lee and Kim(2007), Chung and Lee(2009, 2010), Kim(2010a, b). Lee and Kim(2007) developed cultural tourist products for the Hampyeong Butterfly Festival, which is the representative festival for Hampyeong Region in the South Jeolla Province. They used butterflies as motifs and applied them to neckties. To promote the Plum Flower Festival of Gwangyang, Kim(2010c) reinterpreted the image of a Plum Flower into a more modernized version and applied it to neckties, scarves, and tshirts. Chung and Lee $(2009,2010)$ have proposed cultural product design developments for the promotion of cultural tourism festivals, and their focus is on the six festivals of the highest class in their types chosen by the Ministry of Culture, Sports, and Tourism from 2000 to 2008, including the Andong International Masked
Dance Festival, Boryeong Mud Festival, Kangjin Celadon Cultural Festival, Jinju South River Light Festival, Choongju World Martial Arts Festival, and Muju Firefly Festival. The study's aim is to revitalize cultural tourism festivals and improve the regional image by proposing distinct fashion cultural product designs that use the region's cultural resources and by researching the state of cultural products in those festivals. Product development was done by determining four items for each festival type and using the cultural resources to design fashion cultural products. Therefore, the significance of this study is that it proposed a detailed process for Iksan City and its local government to go about developing cultural products and outline strategies to promote its region especially during the time when the cultural products market is expanding.

\section{Results and Discussion}

\subsection{Developing motif designs}

The design utilized for the necktie motifs were the Sumakse tiles, which are the Mireuksaji artifacts that were used as part of the wooden architecture. The specific Sumakse tiles used were the double-row chrysanthemum tiles and the phoenix tiles. The colors for the neckties were sky and magenta for the double-row chrysanthemum tiles and gray and green for the phoenix tiles. The value of each color was expressed in CMYK percentages as shown in Table 4.

The motif designs applied to the scarves were also used from the Mireuksaji artifacts that were found in the wooden architecture including the double-row lotus tiles and the bronze horse figure. The bronze horse figure was placed under the altar when building a wooden building and was known to be used as a spell or a charm. The reasoning behind the charm was that in case of a fire in the building, people should run fast like a horse and escape. The colors

Table 4. Motif designs and colorway application for necktie design

(CMYK : \%)

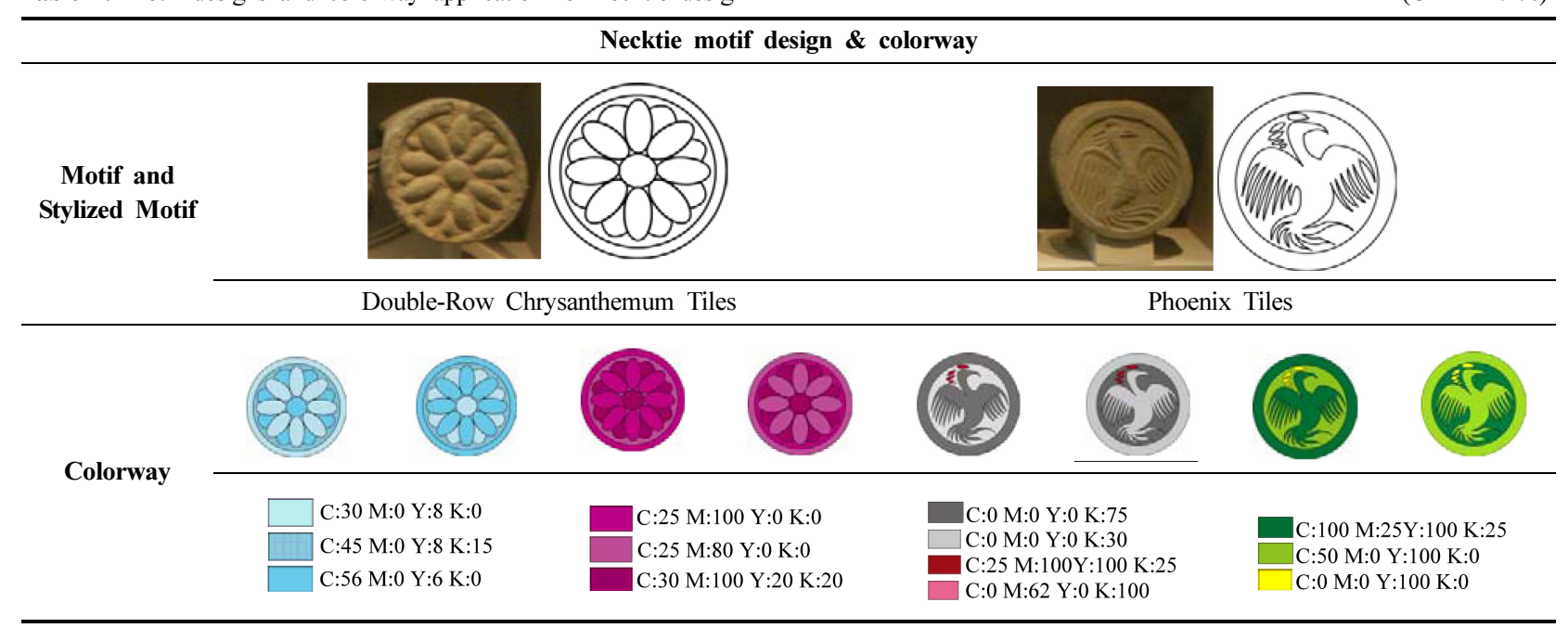




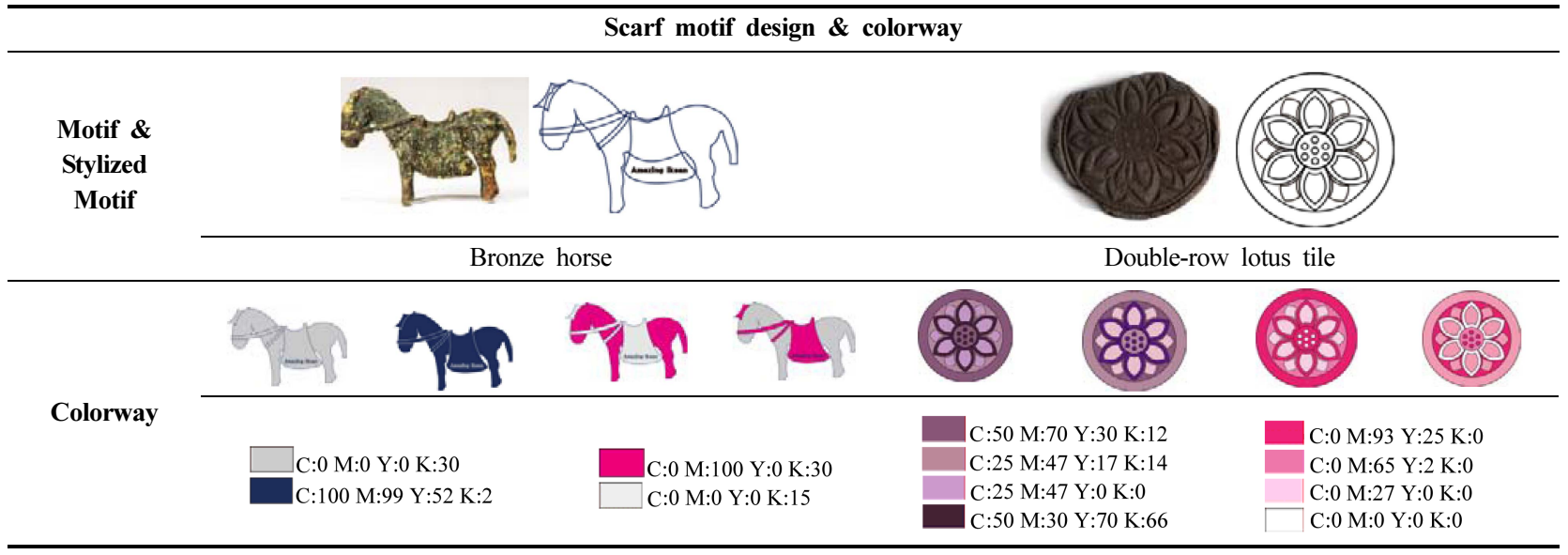

applied to the scarves were gray, navy, pink, and violet ranges and the value of each color was expressed as CMYK percentages as seen in Table 5. Specifically, the slogan for Iksan City("Amazing Iksan") was combined with the bronze horse figure to stress the image of being a tourism product(Table 5).

\subsection{Designing fashion cultural products}

\subsubsection{Necktie designs}

As seen in Table 4, the double-row chrysanthemum tiles and the phoenix tiles were used to develop the two motifs for the necktie designs. Four different color ranges were applied then two different shades from each color were combined creating tone-on-tone color coordination. The motifs with the colors applied were tilted 45 degrees according to the characteristic of neckties and was developed into a pattern. The different patterns were attempted by scaling each motif by $100 \%, 50 \%$, and $30 \%$. A total of 8 necktie designs were developed(Table 6).

\subsubsection{Scarf designs}

The two motifs for the scarves were also developed as in Table 5

Table 6. Necktie designs using the double-row chrysanthemum and the phoenix motifs

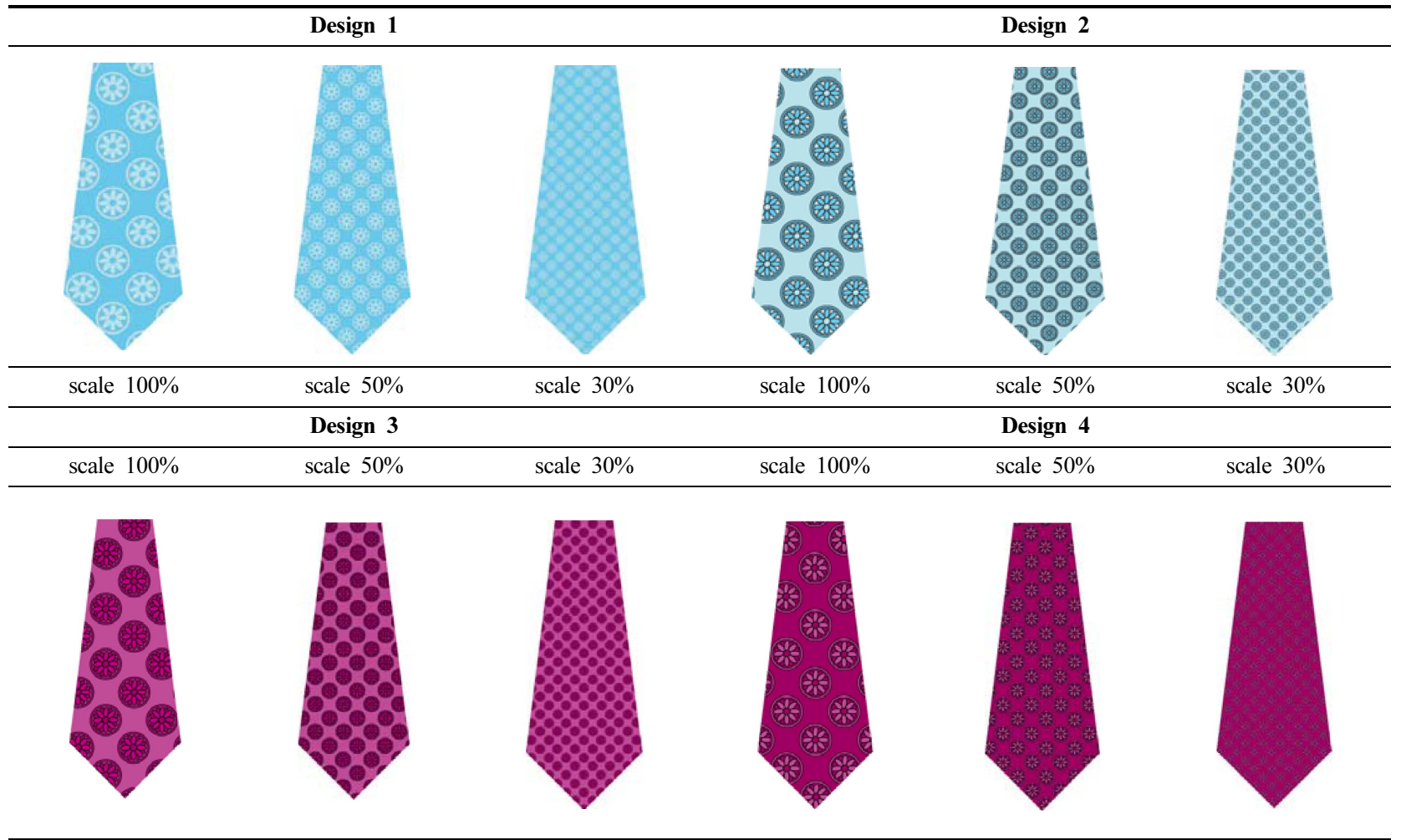


Table 6. Necktie designs using the double-row chrysanthemum and the phoenix motifs(continued)

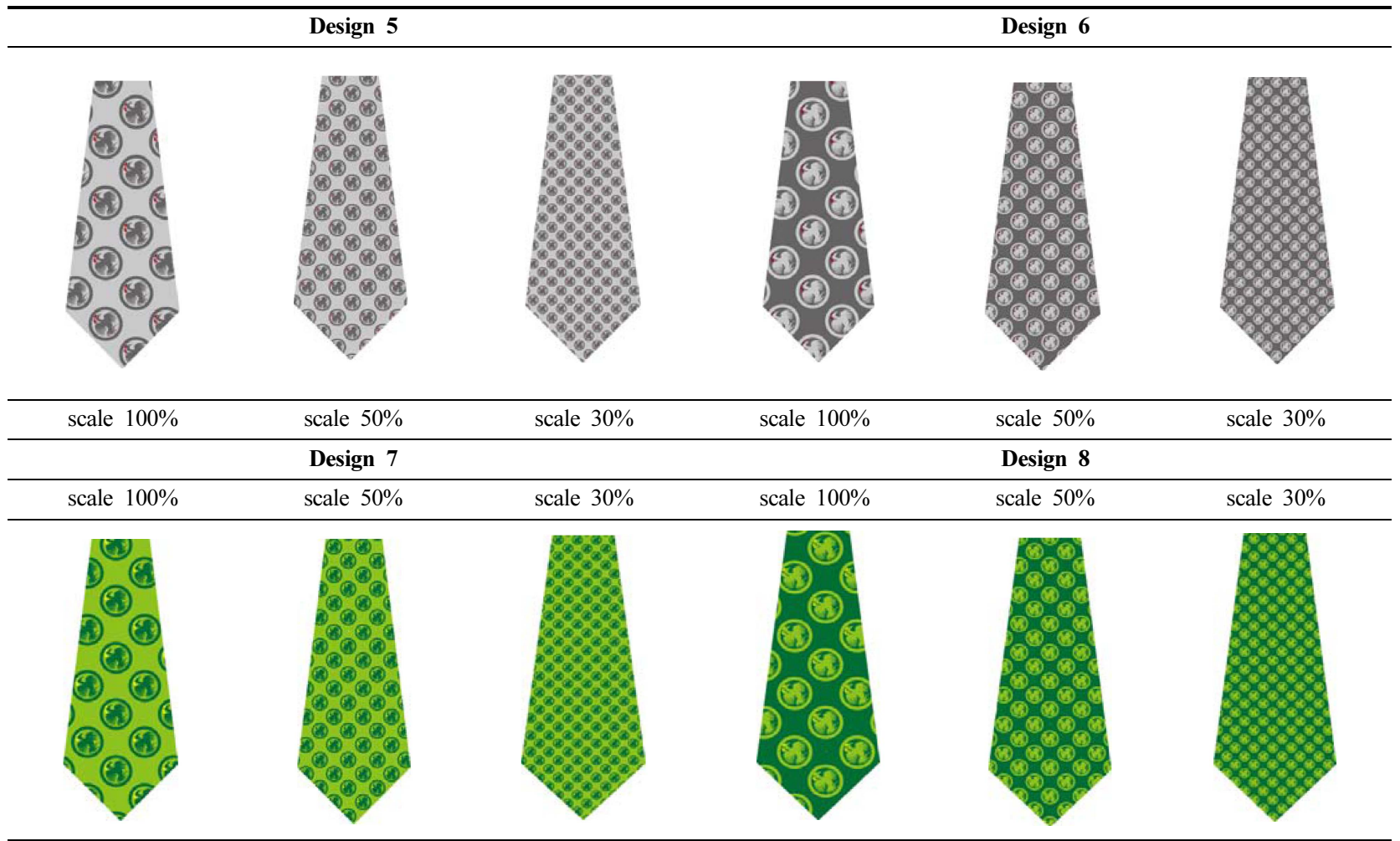

using the bronze horse figure and the double-row lotus tiles. Four different color ranges were applied, then, for each color range, two different shades were combined creating tone-on-tone color coordination. The development of the motifs were first tilted by 45 degrees to match the rectangular pattern of the scarf and applied to a pattern and then the motifs were rotated up and down and applied to a zigzag pattern. A total of 8 designs were developed(Table $7 \&$ 8). The scarf designs using the double-row lotus tiles as the motif was tilted 45 degrees and applied into a pattern and developed into four different designs(Table 9). For the scarves also, the different patterns were attempted by scaling each motif by $100 \%, 70 \%$, and $50 \%$ and a total of 12 designs were developed.

Table 7. Scarf designs using the bronze horse motifs I

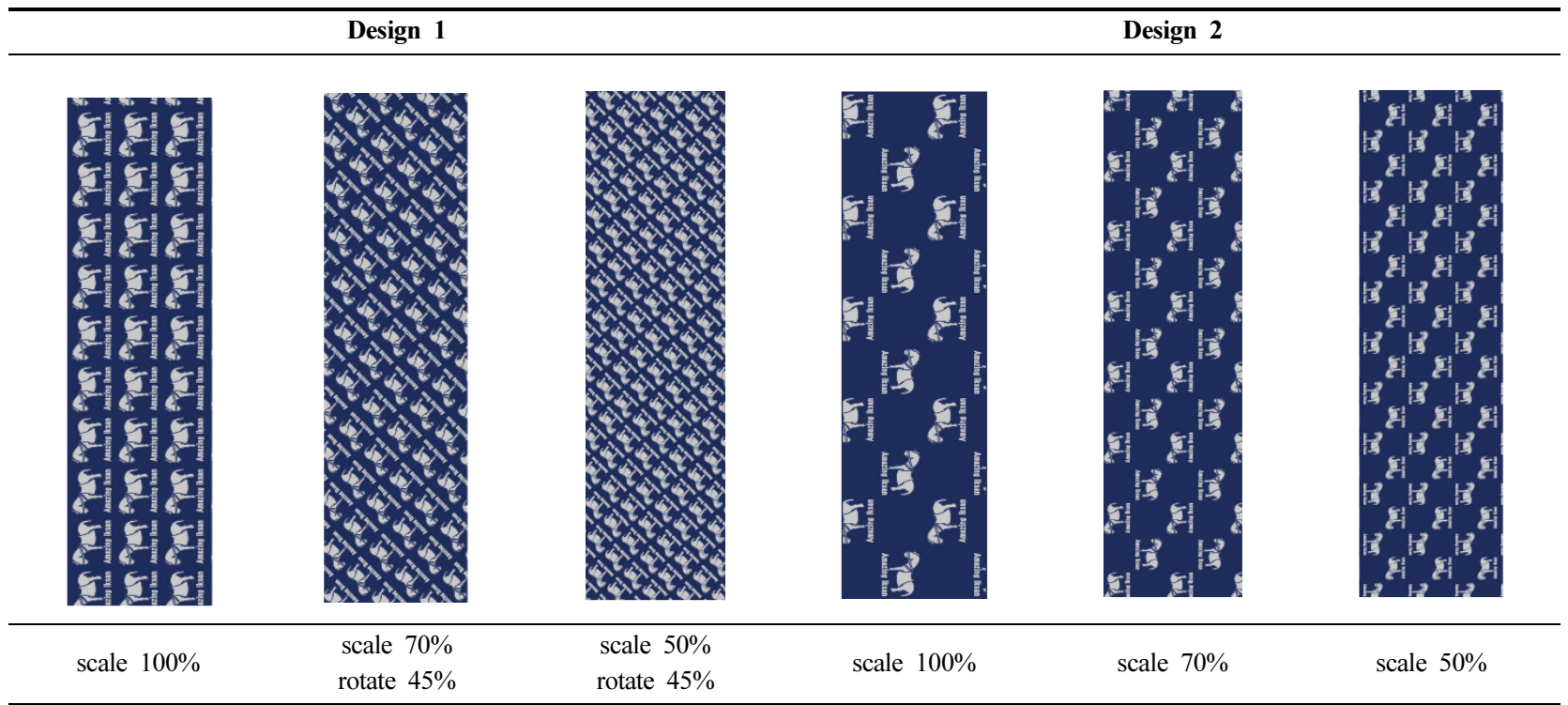


Table 7. Scarf designs using the bronze horse motifs I(continued)

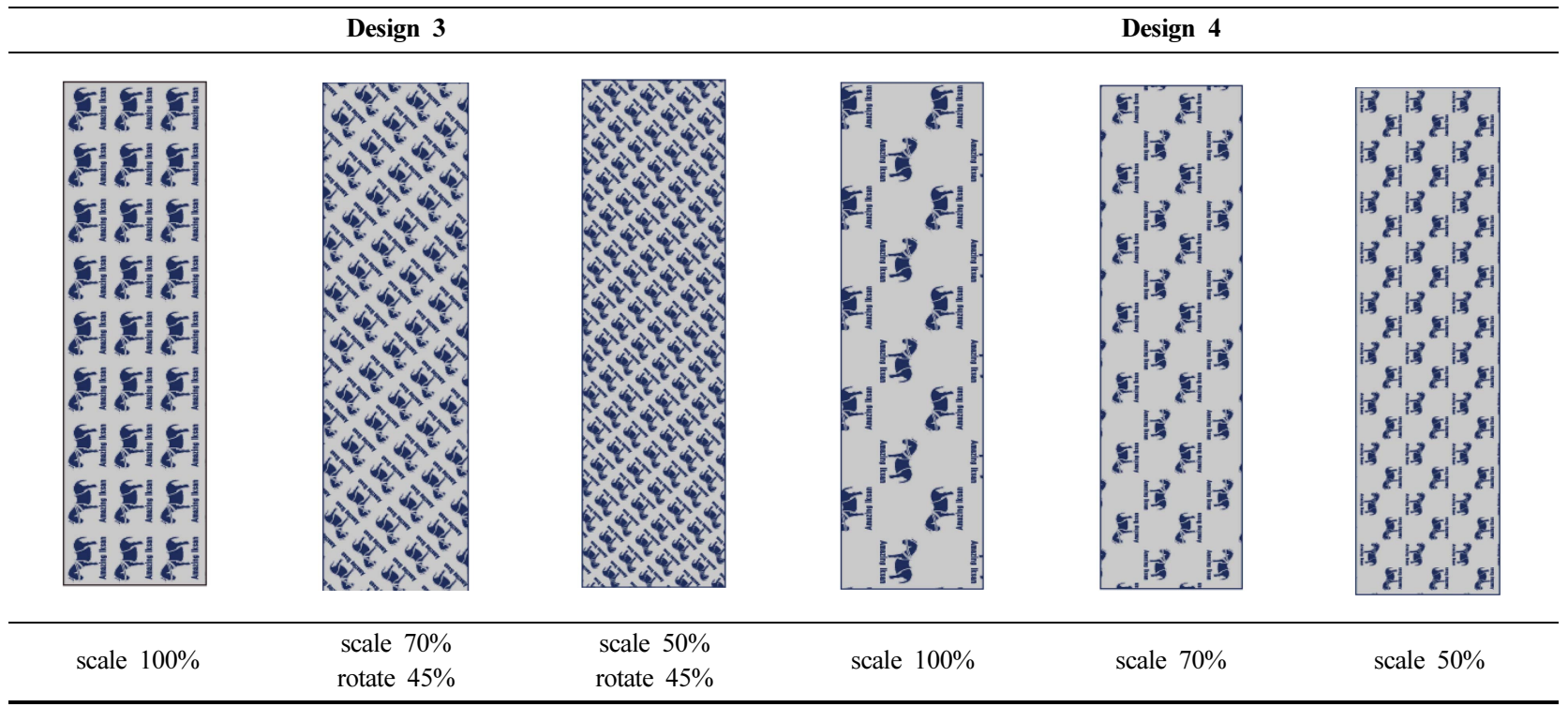

Table 8. Scarf designs using the bronze horse motifs II

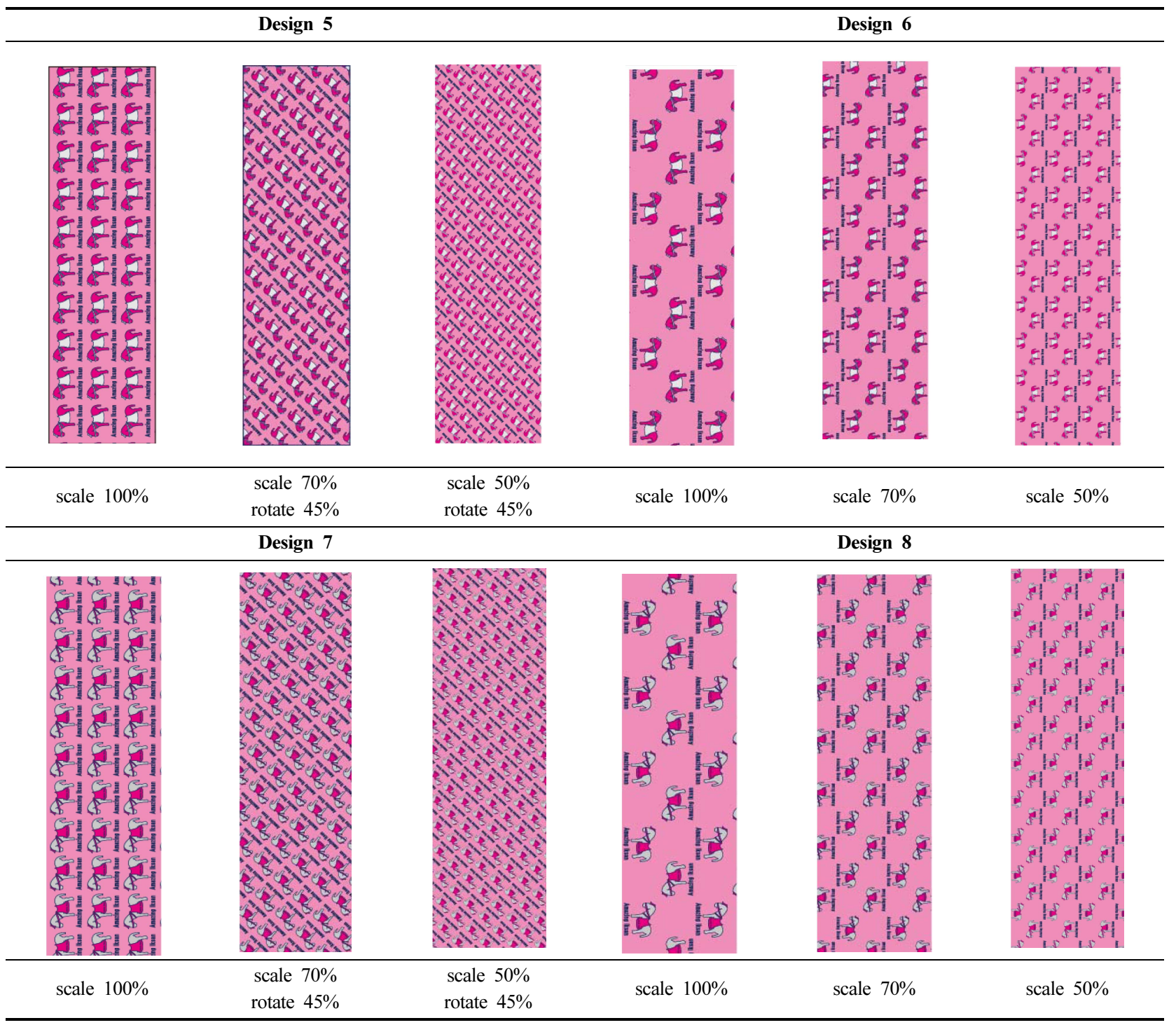


Table 9. Scarf designs using the double-row lotus motifs

\begin{tabular}{|c|c|c|c|c|c|}
\hline \multicolumn{3}{|c|}{ Design 9} & \multicolumn{3}{|c|}{ Design 10} \\
\hline 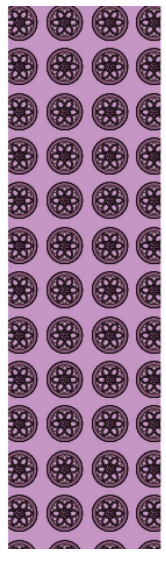 & & 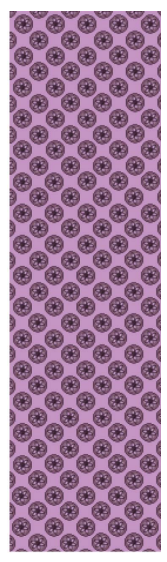 & 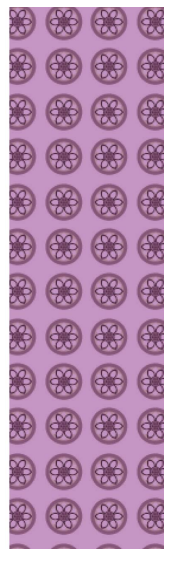 & & 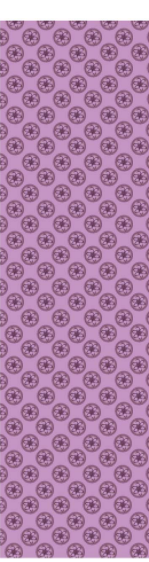 \\
\hline scale $100 \%$ & scale $70 \%$ & scale $50 \%$ & scale $100 \%$ & scale $70 \%$ & scale $50 \%$ \\
\hline \multicolumn{3}{|c|}{ Design 11} & \multicolumn{3}{|c|}{ Design 12} \\
\hline 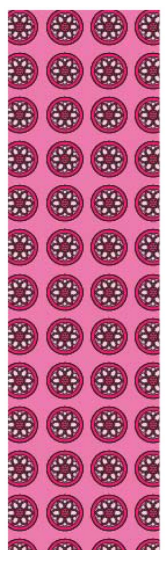 & 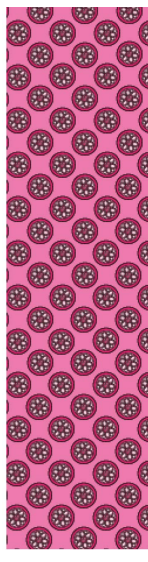 & 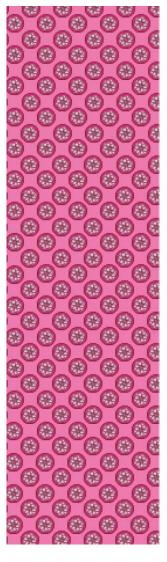 & 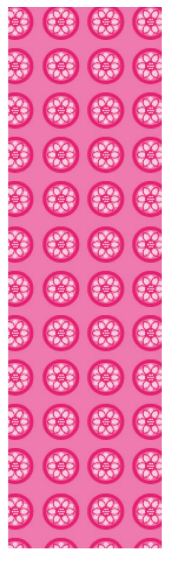 & & 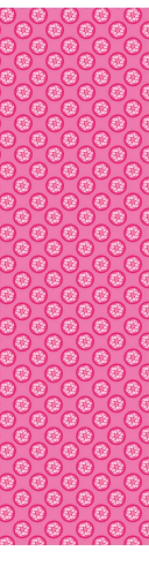 \\
\hline scale $100 \%$ & scale $70 \%$ & scale $50 \%$ & scale $100 \%$ & scale $70 \%$ & scale $50 \%$ \\
\hline
\end{tabular}

\section{Conclusion}

The purpose of this study was to develop fashion cultural products that would appeal to consumers based on artifacts from Iksan's representative archeological site, the Mireuksaji, which forms the center of the Baekje culture. Adobe Illustrator CS4 and Adobe Photoshop CS4 were used to reconstitute motifs from the Sumakse tiles and the bronze horse figure, both artifacts displayed in the Mireuksaji Museum. And these motifs were modified and stylized to make different patterns and these patterns were repeated in various ways to be applied to necktie and scarf designs.

For the necktie motifs the double-row chrysanthemum and phoenix tiles were used and for the scarf motifs the double-row lotus tiles and bronze horse figure were used. The colorway for the necktie motifs were sky and magenta for the double-row chrysan- themum tiles and gray and green for the phoenix tiles. For the scarf motifs, gray, navy, and pink were used for the bronze horse and pink and violet ranges were used with the double-row lotus tiles. The value of each color was shown in CMYK percentages. The Iksan brand slogan "Amazing Iksan" was combined with the bronze horse to emphasize the local cultural identity as displayed in the tourist products.

The necktie designs were developed by tilting the motif by 45 degrees according to the characteristic of neckties. These motifs were applied to create a pattern by repetition, and different patterns were attempted by scaling each motif by $100 \%, 50 \%$, and $30 \%$. A total of 8 necktie designs were developed. For the scarf designs a total of 12 designs were presented. First, the motif using the bronze horse was tilted by 45 degrees and this motif was rotated creating a zigzag pattern. The scarf designs using the double-row lotus motifs 
were also tilted 45 degrees and repeated to make patterns and these patterns were applied to develop four different designs. The scarf motifs were also scaled each by $100 \%, 70 \%$, and $50 \%$.

The fashion cultural product designs presented in this study will, not simply deal with souvenirs but condenses the region's cultural characteristics into the design development thus providing the groundwork of creating a cultural identity for the Iksan region. In addition, the motifs that were developed in this study can be applied not only to neckties and scarves but also to personal effects such as hats, purses and stationery items, therefore, being highly useful.

Accordingly, it was hoped that acting as a foundation, this study would induce future studies on the development of fashion products based on local culture. Also, the results of these studies will develop competitive promotional materials that will not only introduce local culture but promote the national image of Korea on a global scale.

\section{References}

Kang, K. M., \& Cho, K. H. (2010). The development of neckties as cultural products for tourists: Focusing on expressing a maritime image through the effects of hand-dyeing and DTP technique. Journal of the Korean Society of Fashion Design, 10(3), 55-74.

Kim, H. S. (2010a). Development of the maskdance dress design. Journal of the Korean Society for Clothing Industry, 12(2), 156161.
Kim, S. K. (2010b). A study on the Sites of Baekje temples in Iksan area. Unpublished doctoral dissertation, Dong A University, Busan.

Kim, S. Y. (2010c). Development of design for cultural fashion products based on the Gwangyang Ume flower festival. Journal of the Korean Society of Costumes, 60(4), 18-29.

Kim, S. Y. (2011). Design development of fashion cultural products based on convergence of international exposition Yeosu and regional culture. Journal of the Korean Society of Costumes, 61(1), 58-68.

Chung, K. H., \& Lee, M. S. (2009). Strategies for development of cultural products design for promotion of cultural tourism festivals( I ): Focusing on utilization of local cultural resources. The Journal of the Korean Society of Costumes, 59(7), 17-33.

Chung, K. H., \& Lee, M. S. (2010). Strategies for development of cultural products design for promotion of cultural tourism festivals $(\Pi)$ : Focusing on utilization of local cultural resources. The Journal of the Korean Society of Costumes, 60(2), 51-67.

Lee, J. M. (2002). A study for the fashioned cultural goods development based on the local culture: with priority given to the cultural goods development applied by the butterfly character of Ham Pyung. Unpublished master's thesis, Ehwa Womans University, Seoul.

Lee, S. P., \& Kim, S. H. (2007). A study on Hampyeong butterfly festival cultural products design contents using CAD: Focus on adobe illustrator CS2. The Research Journal of the Costume Culture, 15(5), 760-769.

(Received 18 March 2014; 1st Revised 23 June 2014; 2nd Revised 5 July 2014; Accepted 11 August 2014)

Copyright (C) 2014 (by) the authors. This article is an open access article distributed under the terms and conditions of the Creative Commons Attribution license (http://creativecommons.org/licenses/by/3.0/), which permits unrestricted use, distribution, and reproduction in any medium, provided the original work is properly cited. 